\title{
STUDY OF AN IMPROVED METHOD OF DRAWING WITH THE HELP OF SIMULATIONS USING FEM
}

\author{
${ }^{1}$ Olga KRIVTSOVA, ${ }^{1}$ Nikita LUTCHENKO, ${ }^{2}$ Aleksey KOVALEV, ${ }^{1}$ Zoya GELMANOVA \\ ${ }^{1}$ Karaganda State industrial University, Temirtau, Republic of Kazakhstan, krivcova60@mail.ru \\ ${ }^{2}$ LPP Orken, Temirtau, Republic of Kazakhstan
}

https://doi.org/10.37904/metal.2019.681

\begin{abstract}
In the paper the results of investigation of drawing method including simple drawing and shear by computer simulation were presented. The simulation in Deform program was performed. As basic scheme of drawing the industrial variant of LLP "Kaz-Metiz" was chosen. Both two new variants were the schemes of step and alternating drawing proposed in Krakow University of science and technology. The parameters of stress-strain state (strain effective, average hydrostatic pressure) and also drawing load were studied. The comparison of all three models revealed that on the existing drawing equipment in LLP Kaz-Metiz the implementation of any of two offered drawing schemes is possible. The most optimal variant is the scheme of alternating drawing.
\end{abstract}

Keywords: Drawing, FEM, stress-strain state, load

\section{INTRODUCTION}

Modeling of various deformation processes in metal forming is very important, and this is facilitated by several factors. Modeling allows you to look "inside" the process, to assess the emerging stresses and strains, to predict the appearance of defects, to analyze the physical relationship of the process. Ensure identification of optimal parameters of the tool and the workpiece for the best process. Also, it allows you to simulate almost any process, bypassing expensive experiments. Mathematical modeling is very important to achieve a deeper understanding of the process by analyzing the physical relationships of the process.

Theoretical modeling of the studied technology at the beginning requires the development of an adequate numerical model by the finite element method (FEM). Using the finite element method (FEM) is a modern approach to solving metal forming problems. The advantage of FEM is the possibility of modeling of deformation nonstationary processes. FEM makes it possible to study the dynamics and kinematics of deformation processes in any part of the studied area with great accuracy, taking into account the rheological features of the deformable materials of both homogeneous and heterogeneous structure. In contrast to analytical methods, FEM makes it possible to build more advanced mathematical models, including threedimensional ones, based on a much smaller number of assumptions and limitations. Therefore, the research results obtained with its help are more objective. FEM is a very universal method having a simple physical basis and mathematical form, which is implemented using a flexible algorithm, well adapted for computer solutions [2]. Therefore, modeling of various deformation processes in metal forming is a actual task.

\section{PREPARATION OF MODELS}

A number of studies were carried out at the Krakow University of science and technology AGH (Poland) in 2011-2013 [1-3], the purpose of which was to improve the drawing process by changing the classical scheme of movement of the metal during deformation. The result of these studies is a new drawing scheme that combines drawing and shear in the vertical plane (Figure 1a). In [4-7] it was found that in addition to shear deformation, an effective way to processing of the metal structure is the implementation of alternating deformation. In [8], the authors showed that the intensification of alternating deformation in the volume of deformable metal, and especially in the axial zone of the workpiece by creating new deformation schemes, is an effective way to improve the physical, mechanical and operational properties of the metal with the 
maximum approximation of the size of the finished product to the size of the original workpiece. It is revealed that at alternating deformation the intensity of damage accumulation is less, and the plasticity of the metal is greater than at monotonic deformation.

a)

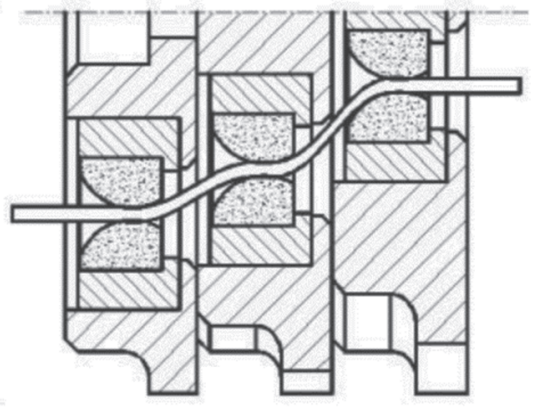

b)

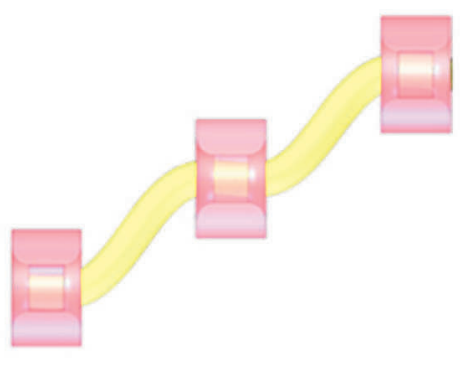

C)

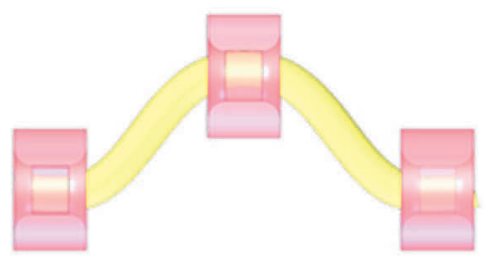

Figure 1 New scheme of drawing

On the basis of these provisions, the authors of work [3] proposed a modified scheme of combining drawing and shear, in which the third die is on the same axis with the first die. This scheme will allow to realize not only shear deformation, but also alternating, which contributes to a more intensive processing of the metal. Figures 1 b-c shows two proposed schemes for combining drawing and shear.

To assess the efficiency of rational choice of the scheme, the task is to conduct a computer simulation of drawing processes in the DEFORM-3D. To build the models, the geometric parameters of the tool and the workpiece are taken from the existing drawing technology in LLP "KAZ-Metiz" for the mode $6.5 \rightarrow 3.2 \mathrm{~mm}$ on the drawing mill $8 \times 900$ № 2 (Table 1).

Table 1 Drawing mode

\begin{tabular}{|c|c|c|c|c|c|c|}
\hline \multirow{2}{*}{ Mode } & \multicolumn{6}{|c|}{ Number of pass } \\
\hline & 1 & 2 & 3 & 4 & 5 & 6 \\
\hline $6.5 \rightarrow 3.2 \mathrm{~mm}$ & 5.63 & 4.92 & 4.34 & 3.86 & 3.46 & 3.2 \\
\hline
\end{tabular}

The first three passes were modeled: $6.5 \mathrm{~mm} \rightarrow 5.63 \mathrm{~mm} \rightarrow 4.92 \mathrm{~mm} \rightarrow 4.34 \mathrm{~mm}$. Reductions of the workpiece after each pass was $0.87 \rightarrow 0.71 \mathrm{~mm} \rightarrow 0.58 \mathrm{~mm}$.

The initial blank had initial dimensions: diameter $-6.5 \mathrm{~mm}$, length $-50 \mathrm{~mm}$. This model was applied to a grid of finite elements evenly distributed over the entire volume of the workpiece. The average size of the final element was $2.3 \mathrm{~mm}$, the number of nodes-13695, the number of elements-54780. According to the technology, steel 70 at a temperature of $20{ }^{\circ} \mathrm{C}$ was chosen as the workpiece material. The rheological properties of the material are taken from the DEFORM-3D database. Used non-isothermal type of calculation, i.e. in addition to the heat transfer tool, the workpiece still gave heat to the environment (temperature $20^{\circ} \mathrm{C}$ ). The adopted value of the coefficient of friction of 0.15 , corresponding to the drawing with dry lubrication. The drawing speed was taken in accordance with the production data according to the current technology and was equal to $4 \mathrm{~m} / \mathrm{s}$. In the design of the two schemes, the value of the angle of displacement of one die relative to the other in the vertical direction was taken 15 degrees. When the alternating scheme drawing of rose for only the second die, the first and third dies were on the same axis.

\section{RESULTS AND DISCUSSION}

As a result of modeling the following models were obtained: drawing with shear (Figure 2a) and alternating drawing with shear (Figure 2b), common scheme of drawing (Figure 2c). The following parameters of stress-strain state were studied: strain effective; average hydrostatic pressure; drawing load. 

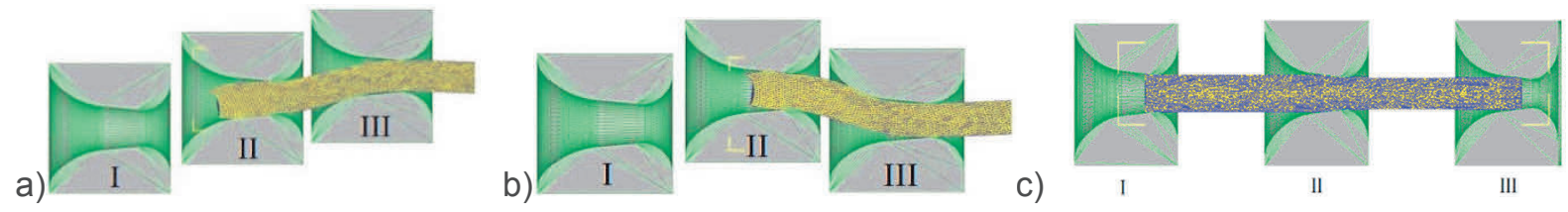

Figure 2 Schemes of drawing

Analysis of the results of the simulation of the common scheme of drawing showed the following. When examining the drawing load during common drawing, it is noted that the force schedule is stepwise, corresponding to the passage of the workpiece through the channels of the die (Figure 3a).

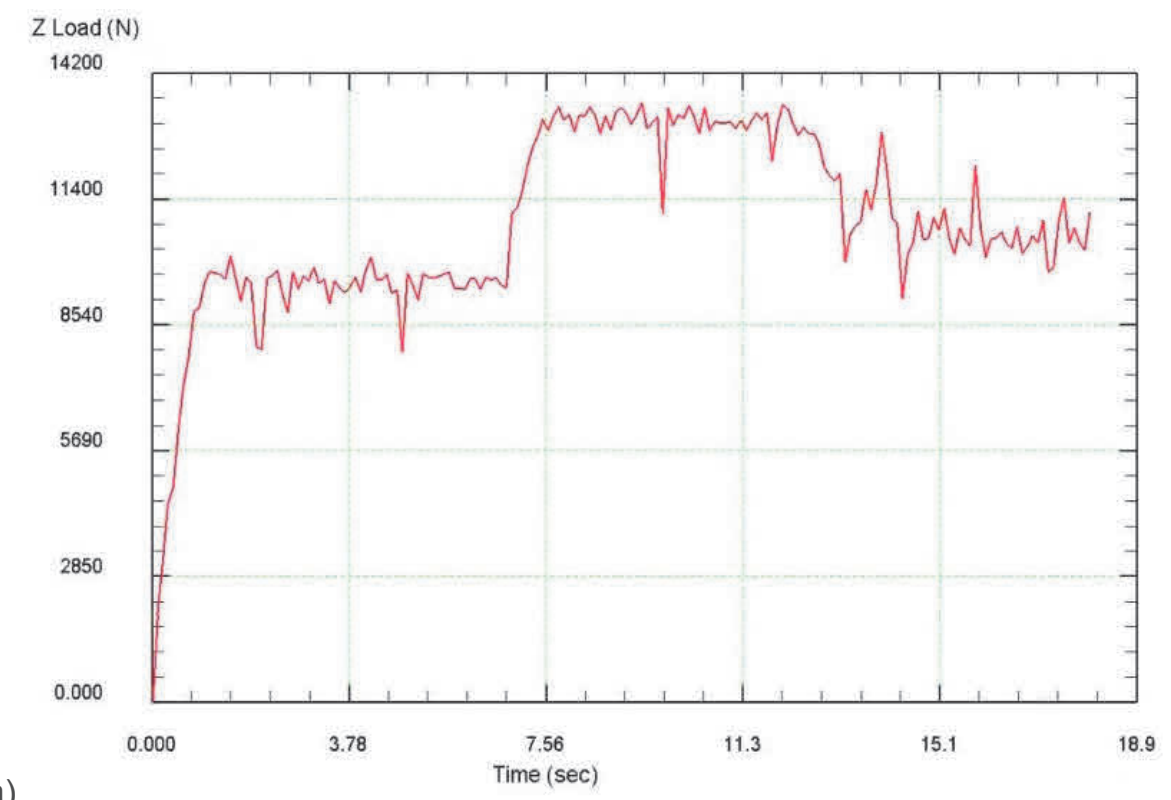

a)

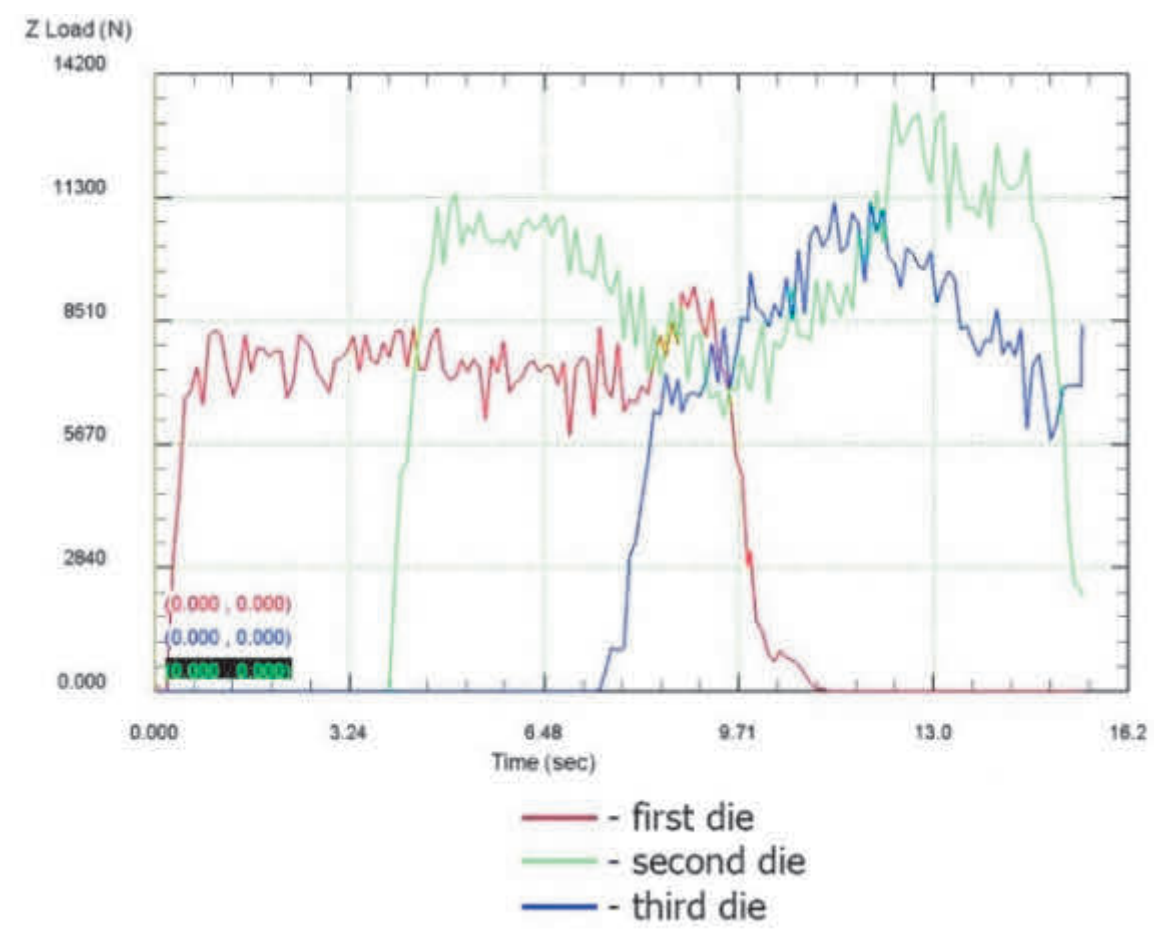

Figure 3a, b Drawing loads 


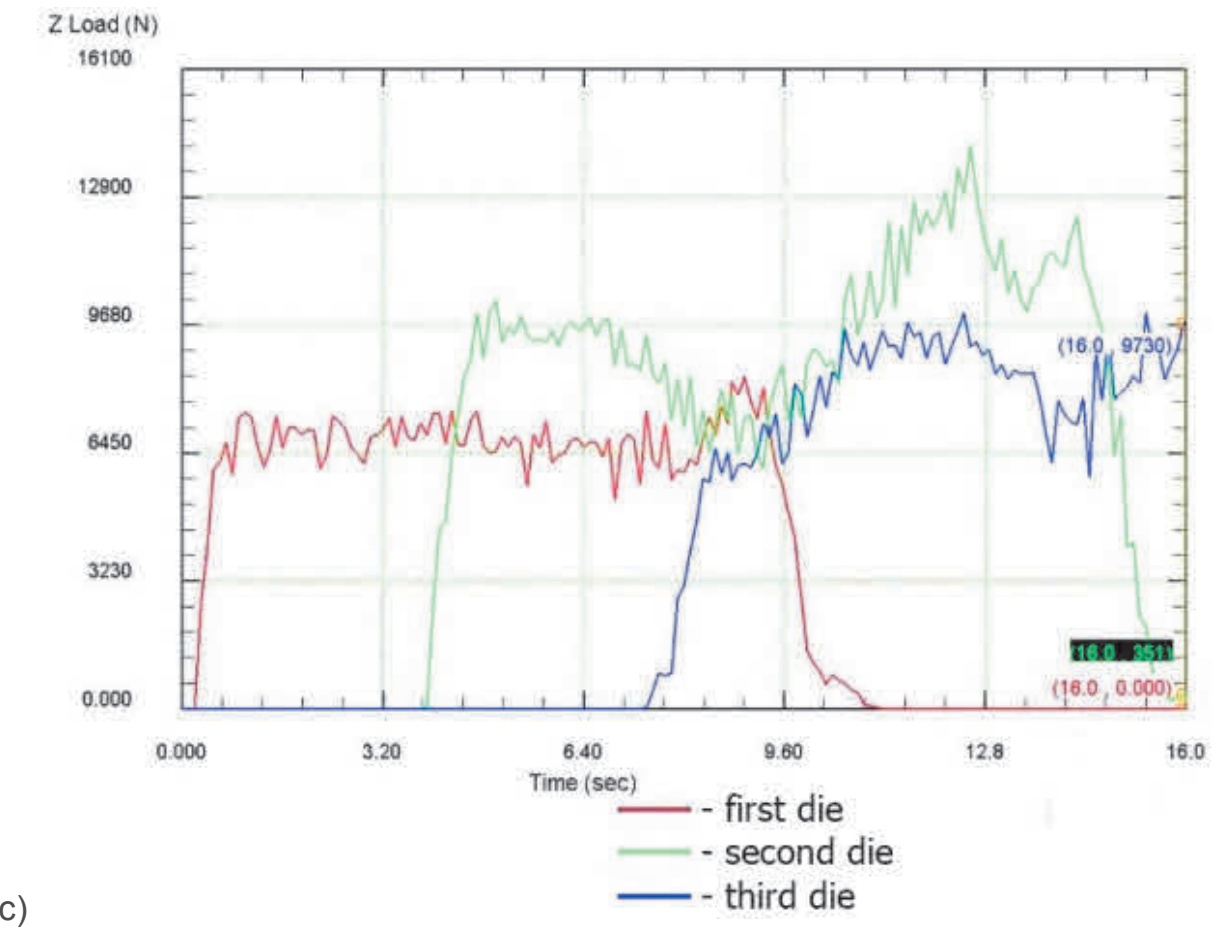

Figure 3c Drawing loads

With the passage of the workpiece in the first die, where the maximum reduction of the workpiece in 0.87 $\mathrm{mm}$. Here a force of about $9.7 \mathrm{kN}$ arises. In contact with the workpiece in the second die implements the reduction of the workpiece in a $0.71 \mathrm{~mm}$. Here, the force added to the force in the first the die, and is the result of $13.6 \mathrm{kN}$. The process of common drawing scheme is characterized by the stability of the flow, which is reflected in the graph of force. Sections of the graph have a horizontal monotonous character. Considering the strain effective, two facts were established (Figure 4a):

1) when passing the channels of the die, the workpiece in the longitudinal direction receives the same level of increase in deformation that is to say, if one area to make several longitudinal sections, in each of them at the same coordinates on the workpiece will be the same strain value;

2 in the cross section, at a distance from the surface to the center of the workpiece strain value is distributed in a monotonically decreasing character. On the surface of the stub, the value of the strain is maximum, in the center - minimal.

a)

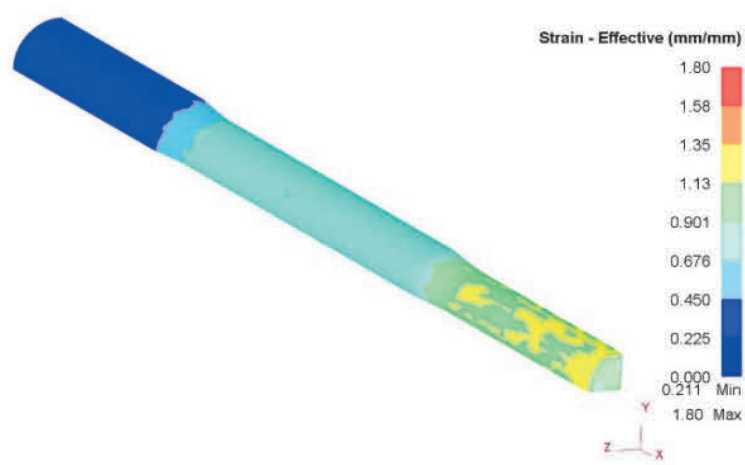

b)

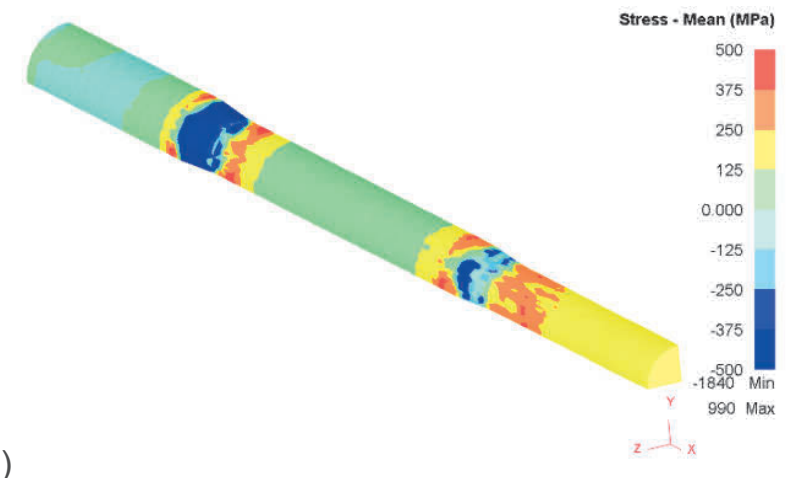

Figure 4 The parameters of stress-strain state in the common drawing 
After the first pass, the value of strain effective was 0.29 in the center and 0.37 on the surface. After the second pass, the value of strain effective was 0.56 at the center and 0.75 at the surface. After the third pass, the value of strain effective was 0.9 in the center and 1.2 on the surface.

When considering the parameter "Average hydrostatic pressure" was revealed extremely uneven distribution in the longitudinal direction of the workpiece (Figure 4b). At the same time, this stress distribution is characteristic of the drawing process as a whole - large tensile stresses are realized along the entire length of the workpiece, due to the pulling action of the drawing mill. However, in the deformation zone of the die, compressive stresses arise, in its absolute value is much higher than the tensile. So, between 1-St and 2nd dies applies tensile stress of about $100 \mathrm{MPa}$. In the area between the 2 nd and 3rd dies acts tensile stress of about $200 \mathrm{MPa}$. In the centers of deformation of the die develop compressive stresses, reach the value $1800 \mathrm{MPa}$.

According to the results of the stepped drawing simulation, the following was revealed. When considering the drawing load, it is noted that the value of the load during the passage of the first die is about $8.5 \mathrm{kN}$, which is distinguishable from the results of the usual drawing scheme by $12 \%(9.7 \mathrm{kN})$. This area has the same horizontal monotonous character (Figure $\mathbf{3 b}$ ). When the workpiece enters the second die and moves it in the vertical direction, the force graph loses its monotony, initially reach the maximum value, the drawing load in the second die begins to decrease as the displacement angle increases. At the moment when the movement of the second die stops, the graph of force in it changes its direction, rushing up. At the same time there is a movement of the third die, here the graph of the force, as in the second die, has no monotony, the force increases as long as the movement of the die does not stop. After that, the force begins to decrease. Analyzing the values of forces during the passage of the workpiece in all three dies, it can be noted that the maximum force values at the step drawing $(13 \mathrm{kN})$ do not exceed the values of the common drawing $(13.6 \mathrm{kN})$. When considering the strain effective parameter was investigated in two stages: 1) At the moment of stopping the movement of the second and third dies, because at these moments, the maximum values of the displacement angles with the previous dies are created. At the first stage, after stopping the second die, the accumulation of deformation is uneven in the cross section of the workpiecethe growth of this parameter is mainly in the diagonal direction. Here, the strain effective value was 0.43 in the center and 0.87 on the surface (Figure 5a); 2) At the second stage, after stopping the third die, the accumulation of deformation continues to develop in the diagonal direction. Here, the value of strain effective, was 0.8 in the center and 1.42 on the surface (Figure $5 \mathbf{b}$ ).
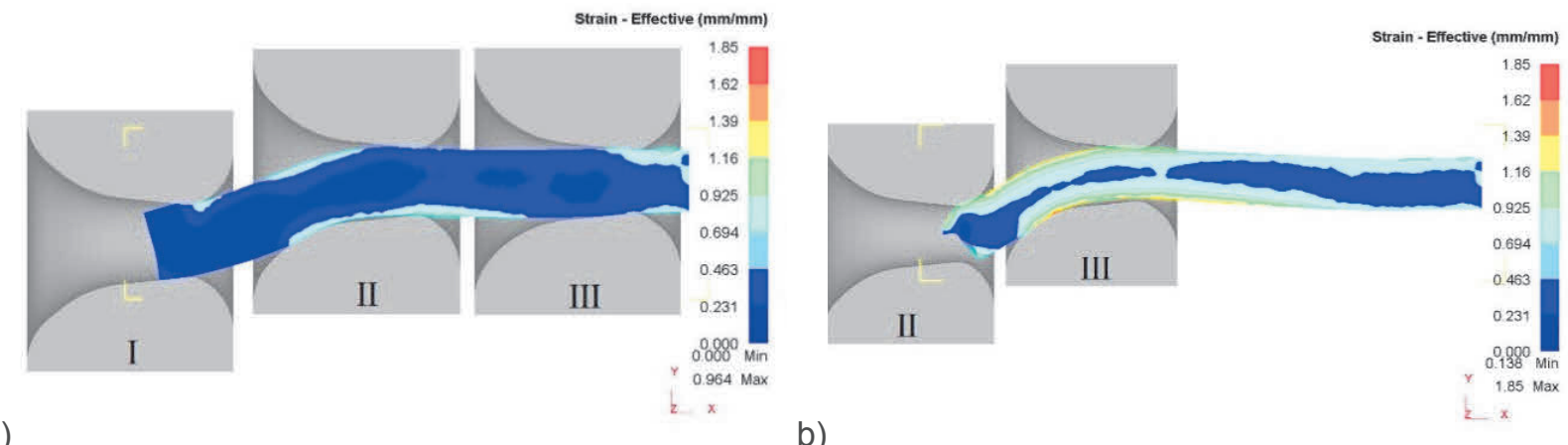

b)

Figure 5 Strain effective of step drawing

When considering the parameter "average hydrostatic pressure", as in the case of drawing the workpiece on the common scheme, it was revealed extremely uneven distribution in the longitudinal direction of the workpiece (Figure 6). There is also an uneven distribution of stresses in the transverse direction-due to the movement of the dies in the vertical direction. As a result, the stresses are separated in the direction of diagonals - tensile stresses act diagonally on one side; compressive stresses act diagonally on the other. 


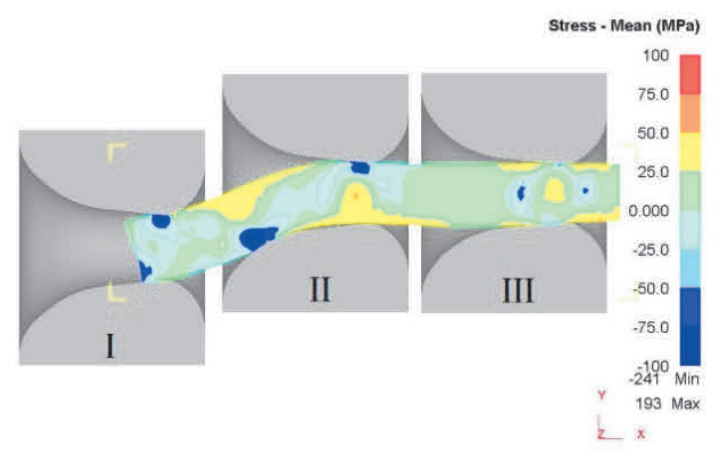

Figure 6 Average hydrostatic pressure of step drawing

At the same time, the compressive stress in its absolute value exceeds the tensile stress by $73 \%$, which is the optimal condition for the stress distribution. So, between first and second dies applies tensile stress to about $55 \mathrm{MPa}$. In the direction of the opposite diagonal develop compressive stresses reaching $200 \mathrm{MPa}$. According to the results of the modeling of drawing the workpiece on the alternating scheme established the following. The stress-strain state and drawing forces of the workpiece in the first two dies are identical to those in the step drawing model. Therefore, in the model of alternating drawing of the workpiece parameters were considered only for the third die.

When considering the drawing load during the alternating drawing, can be noted the following. The values of the forces in the first two dies, as well as the character of the curves on the graph, are similar to the step drawing (Figure 3c). The nature of the force graph in the third die is the same as in the stepped drawing scheme. However, the overall level of force is reduced by about $15 \%$ and is about $9.7 \mathrm{kN}(11.3 \mathrm{kN}$ in step drawing).

When considering the strain effective revealed the following. Accumulation, as in the previous model, has a diagonal character (Figure 7a). After stopping the third die, the accumulation of deformation continues to develop in the diagonal direction. Here, the value of the strain effective parameter was 0.93 in the center and 1.54 on the surface. The average hydrostatic pressure, as in the case of step drawing, has an uneven distribution in the longitudinal and transverse direction of the workpiece (Figure 7b). As a result of the action of stresses are divided in the direction of diagonals - on one diagonal tensile stresses; on the other diagonal - compressive.
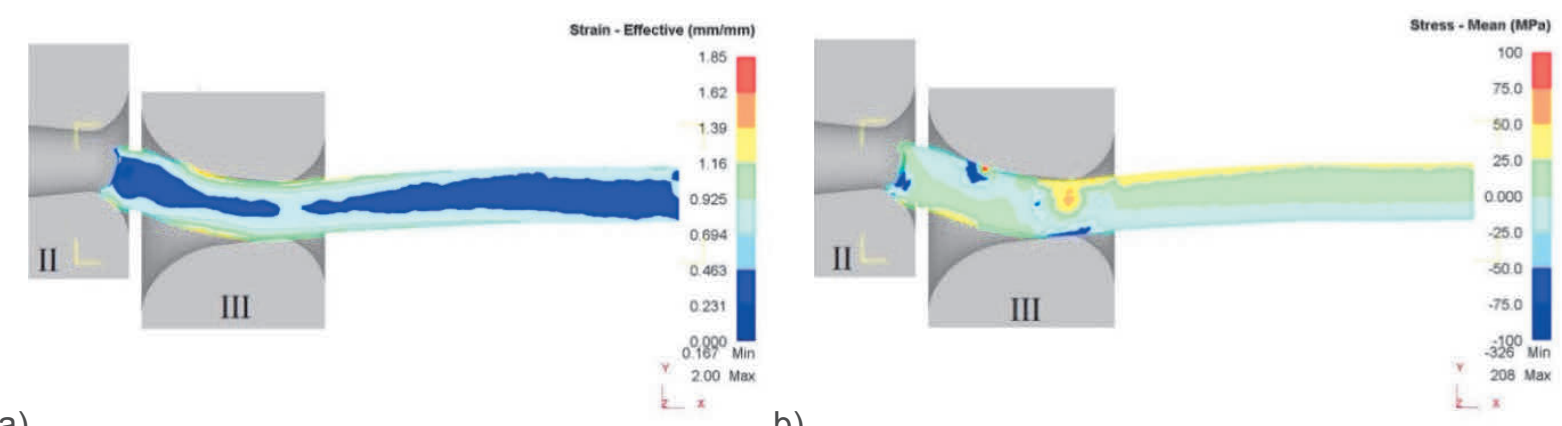

a)

Figure 7 The parameters of stress-strain state in the alternating drawing

At the same time, compressive stresses exceed tensile stresses by $70 \%$ in their absolute value. So, in the area between the second and third dies acts tensile stress equal to $75 \mathrm{MPa}$. In the direction of the opposite diagonal develop compressive stresses reaching $250 \mathrm{MPa}$. 
Having considered all three models of drawing of a steel wire, and also having estimated arising values of forces and the general picture of distribution of parameters of the stress-stain state, it is possible to make a number of practical recommendations on improvement of technological process of drawing in KAZ-Metiz LLP»: 1) On the existing drawing equipment in Kaz-Metiz LLP it is possible to implement any of the two proposed drawing schemes, since the resulting values of the efforts in both cases do not exceed the values in the case of ordinary drawing. In case of choosing a new drawing scheme, a complete modernization of the drawing mill with a more powerful analog will not be required; 2) Comparing the step and alternating drawing scheme, the unambiguous advantages of the second option were revealed. Due to the implementation of not only shear, but also alternating deformation, the workpiece receives a higher increase in the accumulated deformation at the same levels of reduces in the dies; 3) For the implementation of any of the two proposed schemes of drawing it is necessary to provide an additional installation that implements the shift of the dies in the vertical direction

\section{CONCLUSION}

Computer simulation of the existing and two proposed drawing schemes is carried out. The emerging drawing loads were considered, as well as the main parameters of the stress-stain state - strain effective and the average hydrostatic pressure. As a result of comparison of all three models it is revealed that on the operating drawing equipment in KAZ-Metiz LLP implementation of any of two offered schemes of drawing is possible. The most optimal variant is the scheme of alternating drawing.

\section{ACKNOWLEDGEMENT}

Work is performed under the non-state funded theme "Development of technology for production of wire products assortment in conditions of LLP "Kaz-Metiz»" (Customer - LLP Kaz-Metiz).

\section{REFERENCES}

[1] WIELGUS, M., MAJTA J., LUKSZA J. and PAĆKO P. Effect of Strain Path on Mechanical Properties of Wire Drawing Products. In 13th International Conference on Metal Forming. 2010. pp. 490-493.

[2] MAJTA J., MUSZKA K., DYMEK S., DZIEDZIC D. and KOPYŚCIAŃSKI M. Study of the Microstructure and Properties of Microalloyed Steel Wires Fabricated by AAD (Angular Accumulated Drawing).In 14th International Conference on Metal Forming. 2012. pp. 455-458.

[3] MUSZKA K., WIELGUS M., MAJTA J., K. Doniec and STEFANSKA-KADZIELA M. Influence of Strain Path Changes on Microstructure Inhomogeneity and Mechanical Behavior of Wire Drawing Products. Materials Science Forum Vols. 654-656. 2010. pp. 314-317.

[4] LANGDON T.G. The characteristics of grain refinement in materials processed by severe plastic deformation. Rev. Adv. Mater. Sci. 2006. Vol. 13. pp. 6 -14.

[5] TOTH L.S. and GU C. Ultrafine-grain metals by severe plastic deformation. Materials Characterization. 2014. Vol. 92. pp. 1-14.

[6] VALIEV R.Z., ISLAMGALIEV R.K., ALEXANDROV I.V. Bulk nanostructured materials from severe plastic deformation. Progress in Materials Science. 2000. Vol. 45, no. 2. pp. 103-189.

[7] BOGATOV A.A. Mehanicheskie svoystva i modeli razrusheniya metalla. Ekaterinburg: UGTU-UPI, 2002. s.328.

[8] BOGATOV A.A. O razrushenii metallov pri obrabotke davleniem. Kuznechno-shtampovochnoe proizvodstvo. 1997. - no. 8. s. 2-7. 